\title{
Responsibility Attitude and Stimulus Valence in Relation to Recognition and Confidence in Recognition of Words
}

\author{
Kallia Manoussaki \\ University of the West of Scotland, Hamilton, Scotland \\ Email: kallia.manoussaki@uws.ac.uk
}

Received 27 August 2014; accepted 20 July 2015; published 23 July 2015

Copyright (C) 2015 by author and Scientific Research Publishing Inc. This work is licensed under the Creative Commons Attribution International License (CC BY). http://creativecommons.org/licenses/by/4.0/

(c) ()

\section{Abstract}

Perceived responsibility may have significant cognitive consequences for both clinical and nonclinical groups. Under conditions of increased responsibility, individuals have been found to show a positive memory bias, but also a decline in metamemory for salient stimuli. Stimulus salience enhances retrieval by means of directive attention, but may actually impede metamemory, especially among anxious populations. It has been suggested that for OCD patients and nonclinical participants with OCD symptoms, progressive exposure to emotionally salient stimuli worsens confidence in memory, while having no effect in memory accuracy. Perceived responsibility is associated with a positive memory bias for negative stimuli with reduced memory confidence. The current study investigated the possible association in a healthy population among responsibility, measured by the Responsibility Attitude Scale (RAS), recognition and confidence in recognition of words that varied in valence. 85 healthy participants were administered the RAS prior to taking part in a word recognition task. Results indicated that responsibility attitude did not predict memory accuracy or memory confidence for negatively, positively or neutrally valenced words. Furthermore, word valence had no effect on memory confidence but did have a significant effect on memory accuracy. Implications for future research point towards the utilisation of responsibility-relevant stimuli.

\section{Keywords}

Responsibility, Valence, Metamemory, Memory Confidence, Obsessive, Compulsive

\section{Introduction}

Inflated responsibility has been defined as "the belief that one has pivotal power to provoke or prevent subjec- 
tively crucial negative outcomes” (Salkovskis, Rachman, Ladouceur, \& Freeston, 1992), which may be related to situations or to other persons and may have practical or moral consequences (Salkovskis, 1996). It is associated with anxiety, most notably in relation to obsessive compulsive disorder, where it is found to be significantly worse compared to anxious and non-anxious controls (Cougle, Lee, \& Salkovskis, 2007). There has been a difference in the way that responsibility has been understood and defined in psychological literature. For example, responsibility may be defined as charity or leadership. This paper looks at responsibility as an awareness of threat and the accompanying tendency to prevent negative outcomes as well as the related anxiety that comes with that. The current study assesses whether responsibility attitude, conceptualised in this way, affects memory function, specifically recognition and confidence in recognition.

This conceptualisation of responsibility is particularly useful in the context of anxiety and its relationship to cognitive impairment. For example, an individual with OCD might not necessarily experience general, social responsibility or take on leadership roles but may experience acute, exaggerated, personal responsibility for preventing harm to self and others in relation to everyday, often very specific, situations (such as switching off a potentially dangerous electrical appliance). Increased responsibility in this sense leads to an exaggeration of the importance of making the right choice and of the consequences of making the wrong one. Furthermore, it has been observed to have significant (negative and positive) cognitive consequences for both clinical and nonclinical groups in relation to behaviours that were once attributed to memory dysfunction (Radomsky, Rachman, \& Hammond, 2001; Moritz, Wahl, Zurowski, Jelinek, Hand, \& Fricke, 2007). Indeed checking behaviours among individuals with OCD and among non-clinical populations have been linked to inflated responsibility (Freeston \& Ladouceur, 1993; Rheaume, Freeston, Dugas, Letarte, \& Ladouceur, 1995). Importantly, memory problems attributed to OCD such as those associated with compulsive checking are now investigated in relation to anxiety (including feelings of responsibility) and its impact on metamemory (Tallis, 1997; Mancini, D’Olimpio, \& D’Ercole, 2001).

The link between responsibility and cognition (in particular attention and memory) has not long been established. Studies involving responsibility and its impact on cognition have focused on populations with obsessive compulsive disorder (OCD), for whom enhanced responsibility is well documented (Hermans, Martens, De Cort, Pieters, \& Eelen, 2003) but have also utilised non-clinical participants with and without obsessive/compulsive symptoms (Salkovskis, 1985; Salkovskis et al., 2000; Smári, Gylfadóttir, \& Halldórsdóttir, 2003; Cougle, Salvoskis, \& Wahl, 2007; Ashbaugh, Gelfand, \& Radomsky, 2006). In recent years studies have revealed that under conditions of perceived responsibility, individuals show a positive memory bias for salient stimuli, but also a decline in metamemory (Radomsky, Rachman, \& Hammond, 2001). Studies primarily on OCD patients, have indicated that an increased sense of responsibility for others has a significant negative impact specifically in terms of "feeling of knowing" and memory confidence, but not memory accuracy (Moritz, Wahl, Zurowski, Jelinek, Hand, \& Fricke, 2007; Cougle, Salvoskis, \& Wahl, 2007; Olley, Malhi, \& Sachdev, 2007; Tolin, Abramowitz, Brigidi, Amir, Street, \& Foa, 2001; Ashbaugh, Gelfand, \& Radomsky, 2006; Hermans, Martens, De Cort, Pieters, \& Eelen, 2003). Perhaps an exaggerated fear of the consequences of "getting it wrong” would increase memory mistrust, despite accuracy remaining unaffected.

Although findings related to the impact of stimulus salience on memory accuracy have not been entirely consistent, it is more or less accepted that moderate but not excessive emotional arousal during encoding benefits recall and recognition (Cahill \& McGaugh, 1998) and that stimulus salience generally enhances retrieval by means of directive attention (Nothdurft, 2002). For healthy individuals, it has been documented that emotionally salient stimuli are processed more than non-salient/neutral stimuli, resulting in a negative memory bias for the later (Melcher \& Piazza, 2011). On the other hand, some findings suggest that, among anxious populations, threatening or stress-provoking stimuli may be processed ineffectively by means of cognitive avoidance. In other words, attention may be directed away from stress-inducing or threat related stimuli, as a means of reducing anxiety, resulting in ineffective processing (Hermans, Martens, De Cort, Pieters, \& Eelen, 2003).

However, a number of studies utilising neutral, non OCD-relevant stimuli showed memory deficits in recall, recognition and memory-for-action among OCD individuals (Ecker \& Engelkamp, 1995; Sher, Frost, \& Otto, 1983; Sher, Frost, Kushner, Crews, \& Alexander, 1989; Rubenstein, Peynircioglu, Chambless, \& Pigott, 1993). On the other hand, later studies, which did use OCD-relevant (and thus emotionally salient) stimuli found no memory deficit (Tolin, Abramowitz, Brigidi, Amir, Street, \& Foa, 2001; Ceschi, Van der Linden, Dunker, Perroud, \& Brédart, 2003; Karadag, Oguzhanoglu, Ozdel, Atesci, \& Amuk, 2005). Salience of stimuli has also been found to positively affect memory of non-occurrences and correct rejections in recognition tests (Ghetti, 2003), 
giving weight to the assumption that higher salience leads to higher memorability.

Emotional stimuli generally are remembered better than non-emotional stimuli in regards to recall (Doerksen \& Shimamura, 2001) and recognition (for example, Dewhurst \& Parry, 2000) with some studies findings that positive words are remembered better than negative words (Hertel \& Parks, 2002) and others findings the opposite (Dewhurst \& Parry, 2000). How stimulus salience affects metamemory or memory confidence is also not entirely clear, but it has been suggested that emotional items are remembered with greater confidence than positive or non-emotional ones (Ochsner, 2000). Strack and Bless (1994) found that participants correctly rejected salient distractor objects with greater confidence than non-salient items. It stands to reason that memory confidence will increase with object salience. However, relatively recent findings seem to suggest that, at least for OCD patients and non-clinical participants with OCD symptoms (especially checkers), progressive exposure to emotionally salient (unsafe) stimuli worsens confidence in memory but has no effect in memory accuracy (Tolin, Abramowitz, Brigidi, Amir, Street, \& Foa, 2001). Despite the fact that threat related stimuli are generally found to provoke a positive attention bias (Muller \& Roberts, 2005) and a positive memory bias, it seems that, at least in OCD populations, confidence for such stimuli appears to decrease with repeated checking (Radomsky \& Rachman, 1999; Radomsky, Rachman, \& Hammond, 2001, Van den Hout \& Kindt, 2003; Radomsky, Gilchrist, \& Dussault, 2006; Dek, van den Hout, Giele, \& Engelhard, 2014).

It appears that, at least for checkers, the positive bias for threatening stimuli is directly related to feelings of responsibility. Conditions where individuals feel responsible for others seem to enhance memory for salient stimuli (Radomsky \& Rachman, 1999). Boschen and Vuksanovic (2007) examined the effect of increased perceived responsibility on memory and confidence in memory among OCD patients and healthy student controls and found that increased personal responsibility significantly reduced memory confidence but not accuracy over repeated trials for the OCD group, but had no real effect on the control group. Perhaps the arousal generated by feelings of heightened responsibility combined with the exposure to personally salient stimuli exacerbates the memory distrust which has already presented in OCD individuals. Indeed, studies dealing specifically with anxiety among OCD patients found that it significantly impacted on both memory and metamemory. Rachman (2002), for example, found that anxiety directly interfered with confidence in memory in OCD patients, as individuals interpreted the arousal triggered by threatening stimuli as incompetence. The decrease in confidence provokes checking behaviours which in turn decreases confidence further, prompting additional checking.

Existing literature indicates that increased feelings of responsibility (associated with the belief that one is responsible for preventing negative consequences for one's self and others) play a role in metamemory and in particular in memory confidence (Ashbaugh, Gelfand, \& Radomsky, 2006). It also, under certain conditions, seems to impact on memory accuracy for salient stimuli (Radomsky, Rachman, \& Hammond, 2001). Feelings of responsibility may enable or exacerbate the cognitive response to emotionally salient stimuli, at least in individuals with OCD symptoms (Moritz, Wahl, Zurowski, Jelinek, Hand, \& Fricke, 2007; Cougle, Salvoskis, \& Wahl, 2007; Olley, Malhi, \& Sachdev, 2007). The cognitive processes that underlie the relationship among responsibility, memory and metamemory are not yet clear so there is room for a systematic exploration of the affective and cognitive components of responsibility and the process by which it affects different aspects of cognition and metacognition including memory and memory confidence. It appears that responsibility impacts upon cognition among clinical populations but not among healthy controls. The aim of the current study is to primarily check if responsibility would predict recognition and confidence in recognition for stimuli that: 1 . are not, by design, personally relevant to the individuals; 2 . have not been rated by the participants themselves for valence; and 3 . are not related to the participants' feelings of responsibility. The study will investigate whether responsibility attitude, as measured by the Responsibility Attitude Scale (RAS) (Salkovskis, Wroe, Gledhill, Morrison, Forrester, Richards, Reynolds, \& Thorpe, 2000), can predict verbal recognition and confidence in verbal recognition for words that differ in emotional valence in a healthy population, with stimuli that are not personally relevant.

\section{Methods}

\subsection{Participants}

Eighty-five male (mean age 22.38 years old) and female (mean age 20.66) students from the University of the West of Scotland with no history of a neurological condition were opportunistically sampled on the Hamilton campus, South Lanarkshire. 


\subsection{Design}

Regression analysis was utilised to investigate whether scores on the Responsibility Attitudes Scale predicted memory accuracy and confidence in memory accuracy for negative, positive and neutral words. In addition, $\mathrm{t}$ tests were utilised to assess possible differences in confidence and accuracy among negative, positive and neutral words. It is hypothesised that RAS will significantly predict confidence in word recognition for all words, but significantly more for negative and positive words, compared to neutral words. RAS will not predict word recognition itself for salient or non-salient words. It is also hypothesised that both positive and negative words will be recognised better than neutral words and that negative words will be recognised better than positive words. Finally confidence in recognition will also be greater for the salient (positive and negative) compared to the neutral words.

\subsection{Materials}

1. Responsibility Attitudes Scale (RAS) (Salkovskis, Wroe, Gledhill, Morrison, Forrester, Richards, Reynolds, \& Thorpe, 2000): The RAS is a general belief, responsibility assumptions scale. It is a 7 point Likert Scale questionnaire, comprising of 26 questions, the mean score of which makes up each participant's total score. The response options are assigned as follows: $1=$ totally agree, 2 = agree very much, $3=$ agree slightly, $4=$ neutral, 5 = disagree slightly, 6 = disagree very much, 7 = totally disagree. RAS total scores range from 26 (high) to 182 (low). The current study used an on-screen version of the RAS.

2. For the memory task, a Superlab script was designed for the purpose of presenting the participants with 120 words (comprising of an equal number of negative, positive and neutral words) and to collect recognition and confidence data from each individual participant.

60 words (comprising of 20 positive, 20 negative and 20 neutral words) were presented during the learning phase. Then the same words along with 60 new words (again comprising of 20 positive, 20 negative and 20 neutral words) were presented during the recognition phase. The words were sourced and grouped for valence from the ANEW depository (Bradley \& Land, 2010) and then matched for frequency by utilising the data base provided by Leech, Rayson and Wilson (2001) (an example of the words used can be viewed in Appendix A).

\subsection{Procedure}

The participants were tested individually, in a quiet room, seated on a chair facing a computer screen. They were first asked to complete the RAS on screen in their own time. Instructions were presented to them on screen. Upon pressing the space bar to initiate the on-screen questionnaire, each question appeared separately, followed by the answer options and the participant was required to press a key when ready to move on to the next question. After completion of the RAS, the word-learning trial began. 60 randomized words were presented on a computer screen, which the participants were asked to attend to. They were then presented with a 3 minute on-screen distract or task, in the form of a visual puzzle. During the recognition trial they were shown the 60 words again along with 60 new words, all presented in random order. Instructions were presented on screen. After each word, the participants were asked to press a key indicating whether they recognize the word or not from the previous trial. If the word was recognised, they were asked to press the "O" key on their keyboard (indicating "old"). If the word was not recognised from the previous trial, they were asked to press the " $\mathrm{N}$ " key on the keyboard (indicating "new"). Immediately after pressing the key, they were instructed to press a number key indicating how confident they were of their response. The options ranged from 1 (not confident at all) to 5 (very confident). For both the learning and the recognition trials, each word stimulus remained on screen for 1 second and there was a 1 second interval between each word presentation. The screen was blank (white) between each word presentation. The words were automatically randomized for each trial and were presented in lower case, in Courier New Regular font, size 30 and in standard black colour. The participants were given debriefing sheets at the end of the task.

\section{Results}

The pilot data (half-way point) did reveal a significant model in regards to RAS and confidence in recognition of negative words $(\mathrm{F}(1,42)=9.401, \mathrm{p}=0.004)$. 
However, after the analysis of the remaining data, the model that emerged was non-significant $(\mathrm{F}(1,81)=$ $1.585, p=0.212$, model explaining $0.7 \%$ of the variance). So the overall data indicated that responsibility scores did not predict recognition or confidence on recognition of the words (regardless of valence). Word valence did affect recognition (negative words were recognised better) but not confidence in word recognition.

\begin{tabular}{cccc}
\hline Responsibility Attitude & Cum $^{*}$ & Mean & SD \\
\hline RAS & 111.39 & 4.27 & 0.71 \\
\hline
\end{tabular}

*mean cumulative (total) scores (possible range 26 - 182)

\begin{tabular}{|c|c|c|c|}
\hline Accuracy—Word Recognition & Mean & SD & Number of Words \\
\hline Overall memory accuracy (all words) & 89.36 & 9.12 & 120 \\
\hline Memory accuracy for all “old” words & 42.92 & 8.13 & 60 \\
\hline Memory accuracy for all “new” words & 45.98 & 11.07 & 60 \\
\hline Memory accuracy for positive words (“old” and “new”) & 29.21 & 4.89 & 40 \\
\hline Memory accuracy for negative words (“old” and “new”) & 28.53 & 5.28 & 40 \\
\hline Memory accuracy for neutral words (“old” and “new”) & 29.54 & 4.13 & 40 \\
\hline Memory accuracy for “old positive” words & 13.69 & 3.36 & 20 \\
\hline Memory accuracy for “old negative” words & 15.03 & 3.69 & 20 \\
\hline Memory accuracy for "old neutral” words & 12.38 & 3.48 & 20 \\
\hline Memory accuracy for “new positive” words & 15.52 & 4.22 & 20 \\
\hline Memory accuracy for “new negative” words & 13.50 & 6.22 & 20 \\
\hline Memory accuracy for “new neutral” words & 17.16 & 3.02 & 20 \\
\hline Memory Confidence & Mean & SD & Max Value \\
\hline Overall confidence & 25.34 & 10.18 & 30 \\
\hline Confidence for "old" words & 4.33 & 0.45 & 5 \\
\hline Confidence for "new" words & 4.16 & 3.25 & 5 \\
\hline Confidence when in error (all words) & 15.43 & 6.02 & 30 \\
\hline Confidence when in error (old positive) & 3.42 & 0.89 & 5 \\
\hline Confidence when in error (old negative words) & 3.29 & 1.03 & 5 \\
\hline Confidence when in error (old neutral words) & 3.49 & 0.79 & 5 \\
\hline Confidence when correct (all words) & 12.70 & 5.07 & 15 \\
\hline Confidence when correctly recognising "old” words & 12.99 & 1.33 & 15 \\
\hline Confidence when correctly identifying “new” words & 12.42 & 9.76 & 15 \\
\hline Confidence for positive words (“old” and “new”) & 4.19 & 1.90 & 5 \\
\hline Confidence for negative words (“old” and “new”) & 4.01 & 0.55 & 5 \\
\hline Confidence for neutral words (“old” and “new”) & 4.54 & 4.45 & 5 \\
\hline Confidence for "old positive" words & 4.35 & 0.59 & 5 \\
\hline Confidence for "old negative" words & 4.38 & 0.57 & 5 \\
\hline Confidence for “old neutral” words & 4.27 & 0.66 & 5 \\
\hline Confidence for "new positive” words & 4.03 & 3.65 & 5 \\
\hline Confidence for "new negative" words & 3.64 & 0.78 & 5 \\
\hline Confidence for "new neutral” words & 4.81 & 8.80 & 5 \\
\hline
\end{tabular}


1. RAS (mean) did not predict overall confidence $F(1,81)=0.055, \mathrm{p}=0.815$, with the model explaining just $1.2 \%$ of the variance;

2. RAS (mean) did not predict overall memory accuracy $F(1,81)=0.399, p=0.529$, with the model explaining $0.7 \%$ of the variance;

3. RAS did not predict confidence for positive words $(\mathrm{F}(1,81)=0.510, \mathrm{p}=0.477$, model explaining $0.6 \%$ of the variance), for negative words $(\mathrm{F}(1,81)=1.585, \mathrm{p}=0.212$, model explaining $0.7 \%$ of the variance $)$ or for neutral words $(\mathrm{F}(1,81)=1.023$, $\mathrm{p}=0.315$, model explaining $0 \%$ of the variance);

4. RAS did not predict confidence for inaccurate $(F(1,81)=0.643, p=0.425$, with model explaining $0.04 \%$ of the variance) or for accurate responses;

5. RAS did not predict confidence when the words were correctly recognised $(F(1,81)=0.006, p=0.938$, model explaining $1.2 \%$ of the variance) or when they were correctly rejected $(F(1,81)=0.064, p=0.800$, model explaining 1.2 of the variance);

Negative words were recognised as "old" most accurately followed by positive and then neutral words.

6. There was a significant difference found in terms of memory accuracy between neutral words $(\mathrm{m}=12.38)$, positive words $(\mathrm{m}=13.69)$ and negative words $(\mathrm{m}=15.03)(\mathrm{F}(2,166)=19.531, \mathrm{p}<0.0005)$;

Specifically:

7. There was a significant difference in accuracy between neutral $(\mathrm{m}=12.38)$ and negative $(\mathrm{m}=15.03)(\mathrm{t}(83)$ $=5.586, \mathrm{p}<0.00025$, one tailed);

8. Significant difference in accuracy between neutral $(\mathrm{m}=12.38)$ and positive $(\mathrm{m}=13.69)(\mathrm{t}(83)=-3.400, \mathrm{p}$ $=0.0005$, one tailed);

9. Significant difference between positive $(\mathrm{m}=13.69)$ and negative $(\mathrm{m}=15.03)(\mathrm{t}(83)=3.291, \mathrm{p}=0.0005$, one tailed);

The reverse was true for accurately recognising that a word had not been seen before. Neutral words were correctly identified as "new" most accurately followed by positive and then negative words.

10. Significant differences were found in terms of accuracy between "new" neutral words $(\mathrm{m}=17.17)$, "new" positive words $(\mathrm{m}=15.52)$ and "new" negative words $(\mathrm{m}=13.50)(\mathrm{F}(2,166)=19.267, \mathrm{p}<0.0001)$;

Specifically:

11. A significant difference was found in terms of accuracy between "new" neutral words $(\mathrm{m}=17.17)$ and "new" positive words $(\mathrm{m}=15.52)(\mathrm{t}(83)=-4.015, \mathrm{p}<0.0001)$;

12. A significant difference was found in terms of accuracy between "new" positive words ( $m=15.52)$ and "new" negative words $(\mathrm{m}=13.50)(\mathrm{t}(83)=3.051, \mathrm{p}=0.003)$;

13. A significant difference was found in terms of accuracy between "new" neutral words $(m=17.17)$ and "new" negative words $(\mathrm{m}=13.50)(\mathrm{t}(83)=-5.509, \mathrm{p}=<0.0001)$;

14. Overall, no significant differences found in terms of confidence in memory between neutral $(\mathrm{m}=4.27)$, positive $(4.35)$ and negative $(\mathrm{m}=4.38)(\mathrm{F}(2,166)=1.147, \mathrm{p}=0.320)$.

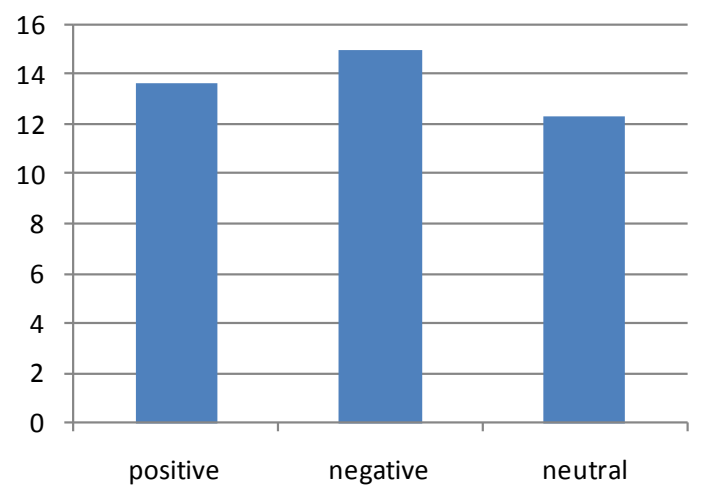

Number of "old" words correctly recognised.

\section{Discussion}

In line with the study's hypothesis, responsibility attitude as measured by the RAS was not found to be a predictor for word recognition, irrespective of word valence. However, contrary to the hypothesis, RAS scores also 
did not predict confidence in recognition, irrespective of word valence or whether the participants' responses in the recognition task were correct or incorrect. On the other hand, the hypotheses were confirmed in regards to the effect of valence on recognition. Specifically recognition was significantly better for negative words than for positive and for positive compared to neutral words. This finding is in line with past research indicating a positive memory bias for negative words (e.g. Kensinger \& Corkin, 2003).

However, word valence did not affect confidence in recognition, which was unexpected given past findings that established links between emotional stimuli and memory confidence (Kensinger, 2007). Even though recognition accuracy was significantly lower for positive compared to negative words and even lower for neutral words, recognition confidence did not mirror this pattern.

In the present design feelings of responsibility are not linked to the outcome of the task. Perhaps this is the crucial factor upon which the relationship between responsibility and metacognition depends. The literature to date points to the fact that perceived responsibility affects cognition when the cognitive task itself is somehow related to the sense of responsibility, especially in terms of the consequences of the participant's performance (for example, Boschen \& Vuksanovic, 2007; Moritz et al., 2007). Moreover, increased responsibility has been associated with expectation of failure (Mancini, D’Olimpio, \& Cieri, 2003), fear of guilt (Mancini \& Gangemi, 2004) and fear of uncertainty (Lind \& Boschen, 2009), all of which are linked to expectancies in regards to the outcome of a behaviour for which an individual feels responsible for.

The fact that preliminary data initially suggests that a link between RAS scores and recognition confidence for negative words certainly warrants further investigation. However, the current findings suggest that for healthy participants at least, responsibility attitude as measured by the RAS, does not predict recognition, or more importantly, confidence in recognition for positive, neutral and negative words, when the words are not personally relevant to the participants or linked to their feelings of responsibility. So the idea that a person who, in general, tends to feel more responsible about the consequences of his/her behaviour, may show a decreased confidence in a word recognition task, compared to a person who scores lower on the responsibility scale, is not supported by these findings. Further exploration may shed light into the precise factors that link increased responsibility to metacognition in a healthy population.

Future research should mainly focus on the ways in which responsibility affects memory confidence in situations when the task stimuli themselves trigger emotional responses that are directly related to the individuals' feelings of responsibility and are matched by expectancies about outcomes in relation to task performance.

\section{Acknowledgments}

The author would like to thank Alex Moncur, Dr M.C. Obonsawin and E. Karali for their contributions to this study.

This study was funded by an internal grant from the University of the West of Scotland.

\section{References}

Ashbaugh, A. R., Gelfand, L. A., \& Radomsky, A. S. (2006). Interpersonal Aspects of Responsibility and Obsessive Compulsive Symptoms. Behavioural \& Cognitive Psychotherapy, 34, 151-163. http://dx.doi.org/10.1017/S1352465805002699

Boschen, R. M., \& Vuksanovic, D. (2007). Deteriorating Memory Confidence, Responsibility Perceptions and Repeated Checking: Comparisons in OCD and Control Samples. Behaviour Research and Therapy, 45, 2098-2109. http://dx.doi.org/10.1016/j.brat.2007.03.009

Bradley, M. M., \& Land, P. J. (2010). Affective Norms for English Words (ANEW): Instruction Manual and Affective Ratings. Technical Report C-2. Gainesville, FL: University of Florida.

Cahill, L., \& McGaugh, J. L. (1998). Mechanism of Emotional Arousal and Lasting Declarative Memory. Trends in Neurosciences, 21, 294-299. http://dx.doi.org/10.1016/S0166-2236(97)01214-9

Ceschi, G., Van der Linden, M., Dunker, D., Perroud, A., \& Brédart, S. (2003). Further Exploration Memory Bias in Compulsive Washers. Behaviour Research and Therapy, 41, 737-747. http://dx.doi.org/10.1016/S0005-7967(03)00040-8

Cougle, J. R., Lee, H.-J., \& Salkovskis, P. M. (2007). Are Responsibility Beliefs Inflated in Non-Checking OCD Patients? Journal of Anxiety Disorders, 21, 153-159. http://dx.doi.org/10.1016/j.janxdis.2006.03.012

Cougle, J. R., Salkovskis, P. M., \& Wahl, K. (2007) Perception of Memory Ability and Confidence in Recollections in Obsessive-Compulsive Checking. Journal of Anxiety Disorders, 21, 118-130.

http://dx.doi.org/10.1016/j.janxdis.2006.03.015 
Dek, E. C. P., Van den Hout, M. A., Giele, C. L., \& Engelhard, I. M. (2014). Automatization and Familiarity in Repeated Checking. Journal of Obsessive-Compulsive and Related Disorders, 3, 303-310. http://dx.doi.org/10.1016/j.jocrd.2014.07.001

Dewhurst, S. A., \& Perry, L. A. (2000). Emotionality, Distinctiveness and Recollective Experience. European Journal of Cognitive Psychology, 12, 541-551. http://dx.doi.org/10.1080/095414400750050222

Doerksen, S., \& Shimamura, A. P. (2001). Source Memory Enhancement for Emotional Words. Emotion, 1, 5-11. http://dx.doi.org/10.1037/1528-3542.1.1.5

Ecker, W., \& Engelkamp, J. (1995). Memory for Actions in Obsessive Compulsive Disorder. Behavioural and Cognitive Psychotherapy, 23, 349-371. http://dx.doi.org/10.1017/S1352465800016477

Freeston, M. H., \& Ladouceur, R. (1993). What Do Patients Do with Their Obsessive Thoughts? Behaviour Research and Therapy, 35, 335-348. http://dx.doi.org/10.1016/S0005-7967(96)00094-0

Ghetti, S. (2003). Memory for Nonoccurrences: The Role of Metacognition. Journal of Memory and Language, 48, $722-739$. http://dx.doi.org/10.1016/S0749-596X(03)00005-6

Hermans, D., Martens, K., De Cort, K., Pieters, G., \& Eelen, P. (2003). Reality Monitoring and Metacognitive Beliefs Related to Cognitive Confidence in Obsessive-Compulsive Disorder. Behaviour Research and Therapy, 41, 383-401. http://dx.doi.org/10.1016/S0005-7967(02)00015-3

Hertel, P. T., \& Parks, C. (2002). Emotional Episodes Facilitate Word Recall. Cognition and Emotion, 16, 685-694. http://dx.doi.org/10.1080/02699930143000491

Van den Hout, M. A., \& Kindt, M. (2003). Repeated Checking Causes Memory Distrust. Behaviour Research and Therapy, 41, 301-316. http://dx.doi.org/10.1016/S0005-7967(02)00012-8

Karadag, F., Oguzhanoglu, N., Ozdel, O., Atesci, F. C., \& Amuk, T. (2005). Memory Function in Patients with Obsessive Compulsive Disorder and the Problem of Confidence in Their Memories: A Clinical Study. Croatian Medical Journal, 46, 282-287.

Kensinger, E. A. (2007). Negative Emotion Enhances Memory Accuracy. Behavioral and Neuroimaging Evidence. Current Directions in Psychological Science, 16, 213-218. http://dx.doi.org/10.1111/j.1467-8721.2007.00506.X

Kensinger, E. A., \& Corkin, S. (2003). Memory Enhancement for Emotional Words: Are Emotional Words More Vividly Remembered than Neutral Words? Memory and Cognition, 31, 1169-1180. http://dx.doi.org/10.3758/BF03195800

Lind, C., \& Boschen, M. J. (2009). Intolerance of Anxiety Mediates the Effect of Responsibility Beliefs on Compulsive Checking. Journal of Anxiety Disorders, 23, 1047-1052. http://dx.doi.org/10.1016/j.janxdis.2009.07.005

Mancini, F., \& Gangemi, A. (2004). Fear of Guilt from Behaving Irresponsibly in Obsessive-Compulsive Disorder. Journal of Behaviour Therapy and Experimental Psychiatry, 35, 109-120. http://dx.doi.org/10.1016/j.jbtep.2004.04.003

Mancini, F., D’Olimpio, F., \& D’Ercole, S. (2001). Responsibility Attitude, Obsession and Compulsion: Further Support in a Non-Clinical Sample. Clinical Psychology and Psychotherapy, 8, 274-281. http://dx.doi.org/10.1002/cpp.292

Melcher, D., \& Piazza, M. (2011). The Role of Attentional Priority and Saliency in Determining Capacity Limits in Enumeration and Visual Working Memory. PLoS ONE, 6, e29296. http://dx.doi.org/10.1371/journal.pone.0029296

Moritz, S., Wahl, K., Zurowski, B., Jelinek, L., Hand, I., \& Fricke, S. (2007). Enhanced Perceived Responsibility Decreases Metamemory but Not Memory Accuracy in Obsessive Compulsive Disorder. Behaviour Research and Therapy, 45, $2044-$ 2052. http://dx.doi.org/10.1016/j.brat.2007.03.003

Muller, J., \& Roberts, J. E. (2005). Memory and Attention in Obsessive Compulsive Disorder: A Review. Journal of Anxiety Disorders, 19, 1-28. http://dx.doi.org/10.1016/j.janxdis.2003.12.001

Nothdurft, H. C. (2002). Attention Shifts to Salient Targets. Vision Research, 42, 1287-1306. http://dx.doi.org/10.1016/S0042-6989(02)00016-0

Olley, A., Malhi, G., \& Sachdev, P. (2007). Memory and Executive Functioning in Obsessive-Compulsive Disorder: A Selective Review. Journal of Affective Disorders, 104, 15-23. http://dx.doi.org/10.1016/j.jad.2007.02.023

Ochsner, K. N. (2000). Are Affective Events Richly "Remembered" or Simply Familiar? The Experience and Process of Recognizing Feelings Past. Journal of Experimental Psychology: General, 129, 242-261. http://dx.doi.org/10.1037/0096-3445.129.2.242

Rachman, S. (2002). A Cognitive Theory of Compulsive Checking. Behaviour Research and Therapy, 40, 625-639. http://dx.doi.org/10.1016/S0005-7967(01)00028-6

Radomsky, A. S., Gilchrist, P. T., \& Dussault, D. (2006). Repeated Checking Really Does Cause Memory Distrust. Behaviour Research \& Therapy, 44, 305-316. http://dx.doi.org/10.1016/j.brat.2005.02.005

Radomsky, A. S., \& Rachman, S. (1999). Memory Bias in Obsessive-Compulsive Disorder (OCD). Behaviour Research and Therapy, 37, 605-618. http://dx.doi.org/10.1016/S0005-7967(98)00151-X 
Radomsky, A. S., Rachman, S., \& Hammond, D. (2001). Memory Bias, Confidence and Responsibility in Compulsive Checking. Behaviour Research and Therapy, 39, 813-822. http://dx.doi.org/10.1016/S0005-7967(00)00079-6

Rheaume, J., Freeston, M. H., Dugas, M. J., Letarte, H., \& Ladouceur, R. (1995). Perfectionism, Responsibility and Obsessive-Compulsive Symptoms. Behaviour Research and Therapy, 33, 785-794. http://dx.doi.org/10.1016/0005-7967(95)00017-R

Rubenstein, C. S., Peynircioglu, Z. F., Chambless, D. L., \& Pigott, T. A. (1993). Memory in Sub-Clinical Obsessive-Compulsive Checkers. Behaviour Research and Therapy, 31, 759-765. http://dx.doi.org/10.1016/0005-7967(93)90006-G

Salkovskis, P. M. (1985). Obsessional-Compulsive Problems: A Cognitive Behavioural Analysis. Behaviour Research and Therapy, 23, 571-583. http://dx.doi.org/10.1016/0005-7967(85)90105-6

Salkovskis, P. M. (1996). Cognitive-Behavioural Approaches to the Understanding of Obsessional Problems. In R. Rapee (Ed.), Current Controversies in the Anxiety Disorders. New York: Guilford.

Salkovskis, P. M., Rachman, S., Ladouceur, R., \& Freeston, M. (1992). The Definition of Responsibility. Paper Presented at the World Congress of Behavioural and Cognitive Psychotherapies, Toronto.

Salkovskis, P. M., Wroe, A. L., Gledhill, A., Morrison, N. Forrester, E., Richards, C. Reynolds, M., \& Thorpe, S. (2000). Responsibility Attitudes and Interpretations Are Characteristic of Obsessive Compulsive Disorder. Behaviour Research and Therapy, 38, 347-372. http://dx.doi.org/10.1016/S0005-7967(99)00071-6

Sher, K., Frost, R. O., Kushner, M., Crews, T. M., \& Alexander, J. E. (1989). Memory Deficits in Compulsive Checkers: Replication and Extension in a Clinical Sample. Behaviour Research and Therapy, 22, 493-502. http://dx.doi.org/10.1016/0005-7967(84)90053-6

Sher, K., Frost, R. O., \& Otto, R. (1983). Cognitive Deficits in Compulsive Checkers: An Exploratory Study. Behaviour Research and Therapy, 21, 357-363. http://dx.doi.org/10.1016/0005-7967(83)90004-9

Strack, F., \& Bless, H. (1994). Memory for Nonoccurences: Metacognitive and Presuppositional Strategies. Journal of Memory and Language, 33, 203-217. http://dx.doi.org/10.1006/jmla.1994.1010

Tallis, F. (1997). The Neuropsychology of Obsessive Compulsive Disorder: A Review and Consideration of Clinical Implications. British Journal of Clinical Psychology, 36, 3-20. http://dx.doi.org/10.1111/j.2044-8260.1997.tb01226.x

Tolin, D. F., Abramowitz, J. S, Brigidi, B. D., Amir, N., Street, G. P., \& Foa, E. B. (2001). Memory and Memory Confidence in Obsessive-Compulsive Disorder. Behaviour Research and Therapy, 39, 913-927.

http://dx.doi.org/10.1016/S0005-7967(00)00064-4

\section{Appendix A}

\begin{tabular}{cc} 
Examples of words presented & \\
\hline crash & owl \\
punish & smoke \\
abortion & bowl \\
cruel & glance \\
grave & knee \\
hostile & paint \\
rape & salt \\
blame & admit \\
burden & location \\
disaster & tower \\
funeral & roof \\
infection & bridge \\
abuse & expensive \\
illness & cabinet \\
suffer & table \\
luxury & happiness \\
brave & miracle \\
comedy & relax \\
\hline
\end{tabular}

